\title{
LUCIA DE LAMMERMMOOR, O SUJEITO DA VOZ EM ESTADO DE LOUCURA
}

\author{
Carolina Dittrich ${ }^{1}$ (UFSC)
}

$E$ É entretanto no estado amoroso que certos sujeitos raqoáveis adivinham de repente que a loucura existe, é possivel,
está bem próxima: uma loucura na qual o próprio amor naufragaria.
Werther

Vivo uma morte viva, carne cortada, sangrante, tornada cadáver, ritmo diminuido ou suspenso, tempo apagado on dilatado, incorporado na aflição...

Julia Kristeva

Resumo: Este trabalho pretende pensar em como, na cena Il dolce suono da ópera Lucia de Lammermmoor, de Donizetti, configura-se a voz feminina em um momento de demência. Para tanto, seria preciso refletir sobre como se constitui o "eu" de Lucia no ponto específico de seu discurso. Formado em uma dinâmica de invocação do outro e configurado no campo do amor, esse discurso abandonado perseguiria a si próprio no vazio do delírio.

Palavras-chave: Lucia de Lammermmoor; voz; loucura.

Enquanto desce as escadas, o coro canta: "ela parece sair de um túmulo". Em sua pálida face um sorriso se desenha, e com a adaga ensanguentada ainda em mãos, Lucia pergunta: "onde está meu marido?”

Assim começa a emblemática cena de loucura $\mathrm{Il}$ dolce suono ${ }^{2}$, terceiro ato da ópera Lucia di Lammermmoor do compositor italiano Donizetti. Datada de 1835, a ópera foi escrita a partir do romance The Bride of Lammermoor $^{3}$, do escocês Walter Scott. Divida em 3 partes, seu argumento, brevemente, é o amor impossibilitado entre Lucia e Edgardo, inimigo mortal de seu irmão, Enrico. Este, para afastá-los, forja uma carta para Lucia na qual escreve que Edgardo está distante e casado com outra. Ela então aceita casar-

-se com Lord Arturo, e, no dia do casamento, seu grande amor reaparece. Lucia perde a razão e mata Lord Arturo na noite de núpcias. Delirante, pensa estar com Edgardo e roga-lhe perdão pela traição. Por fim, Lucia morre; todavia, não sabemos se foi morta, adoeceu, ou se matou. E Edgardo, não suportando a dor, tira a própria vida.

1 Doutoranda do Programa de Pós Graduação da UFSC; Bolsista Capes; E-mail: caroldittrich@yahoo.com.br

2 "O doce som". A passagem aqui descrita pode ser vista no site: <http://www.youtube.com/watch?v=Q3kzqzXHp2>. Acesso em: 12.ago.2012.

${ }^{3}$ A noiva de Lammermmor. 
A cena escolhida para o presente estudo está na peça interpretada pela soprano Natalie Dessay no Metropolitan Opera, em 2011, e possui aproximadamente vinte minutos. O primeiro momento dessa passagem é quando Lucia, logo após ter assassinado seu marido, se junta aos convidados do casamento, que atuam como coro. Nesse ponto, ela inicia um discurso esquizofrênico, e já não percebendo mais nada à sua volta, fala com Edgardo como se este ali estivesse ${ }^{4}$. Na parte subsequente, os instrumentos começam a lhe acompanhar quase que em um movimento de resposta aos seus fluxos de enunciação. Por fim, sem recobrar qualquer consciência, chega a segurar nos braços seu véu como se fosse um bebê e, já medicada, é retirada de cena.

Assim, descrita a passagem, proponho pensarmos a loucura neste trabalho, mesmo que de modo mais amplo, como uma condição da mente que impede que o sujeito estabeleça conexões no campo simbólico com um outro, mais especificamente, a crença de que o simbólico seria o real. Ou ainda, e uma ideia a complementar a outra, pensemos em uma espécie de camada no próprio ser que impossibilite sistemas, ditos "normais", de interação com esse outro; ao mesmo tempo, de acordo com Lacan (1966, p.162-166), o ser do homem não poderia ser compreendido sem sua loucura, assim como não seria o ser do homem se não trouxesse em si a loucura como limite de sua liberdade.

Em História da Loucura (1961), Foucault, ao descrever alguns dentre os "tipos de loucura" já reconhecidos entre os séculos XVIII e XIX, cita a paixão desesperada, ou decepcionada em seu excesso, ou ainda, e sobretudo, a paixão enganada pela fatalidade da morte, que não teria outra saída a não ser a demência. Enquanto houvesse um objeto, tal paixão se configuraria no campo do amor, mas assim que abandonada, perseguiria a si própria no vazio do delírio.

O que se passa no contexto de Lucia não é exatamente a morte de seu amado; está para além da perda: é o luto. Este configura em um caminhar vertiginoso por entre sucessões de emoções heterogêneas. A partir de uma leitura Freudiana, Julia Kristeva (1989) evoca a "estranheza inquietante" (a qual Freud chamava unheimlich), algo de familiar à vida psíquica que se transforma em "estranho", e que em Il dolce suono está presente no próprio delírio da personagem. A perda dessa paixão muniria a alma de uma ausência irreparável, uma violência contra si próprio e que, em um paradoxo, também acalentaria

4 Transcrição do canto na cena: "o doce som de sua voz me capturou/ Oh, aquela voz/ Penetrou no fundo do meu coração/ Edgardo eu sou sua novamente/ Eu fuji dos seus inimigos/ Um arrepio correu pelo meu corpo/ Tremem todas as fibras/ Meus pés vacilam/ Lá, na fonte/ Sente-se comigo na fonte/ Ah, eleva-se o espectro horrivel/ Ele está no partindo/ separando/ O fantasma.../ Vamos nos esconder ao pé do altar" Tradução minha. Opto por deixar registrado aqui apenas a primeira parte do movimento. Também, todas as traduções das obras originais aqui utilizadas foram traduzidas por mim.

A transcrição completa da cena $I l$ dolce suono em italiano pode ser vista no site: $<$ http://classicalmusic.about.com/od/opera/qt/ildolcesuonotxt.htm>. Acesso em: 11.ago.2012. 
pela construção de presenças imaginárias e discursos esfumaçados. Nessa condição, ainda de acordo com Kristeva, a fala se interrompe na impossibilidade de encadear e formular sintagmas (1989, p. 39), pois na dor, a palavra possuiria uma musicalidade frugal que se esgotaria e deitaria no caos. Contudo, estamos tratando do momento de delírio da jovem enamorada que está em um abismo onde os significantes se desmoronam ao não-sentido a partir da recusa da perda do objeto amado.

[...] Segundo Freud, a recusa ou desmentido (Verleugnung) aplica-se à realidade psíquica que ele considerava como sendo da ordem da percepção. Essa recusa seria coisa usual na criança, mas torna-se o ponto de partida de uma psicose no adulto, pois aplica-se à realidade externa. Entretanto, e posteriormente, a recusa encontra seu protótipo na recusa da castração e se especifica constituindo o fetichismo (KRISTEVA, 1989, 47-48).

Primeiramente é necessário elucidar que a ópera é expressão que se realiza em um conjunto de acontecimentos discursivos heterogêneos (texto, música, voz e performance). Seria possível relacioná-la à poética homérica, a qual Cavavero (2011) descreve como possuidora de uma voz narrativa, ou seja, um canto no qual a vocalidade e a oralidade estariam unidas na musicalidade do ato. Há uma ligação substancial com a literatura desde seu nascimento, no início do séc XVII, em que despontam as primeiras óperas, e podemos citar aqui a exibição de Orfeu por Monteverdi, na Itália. Apresentavam temas comumente tomados de obras literárias e eram escritas pelos libretistas, a exemplo de Molina, que compôs Don Giovanni de Mozart.

Pois bem, em Lucia di Lammermmoor, após a personagem ter assassinado o homem com quem acabara de casar, invoca o outro, seu amado, quando diz: "o doce som de sua voz me capturou". A voz dela, numa entonação ainda monótona, procura uma outra voz. Contudo, a resposta não virá. De fato, desde o período medieval era comum que, nas peças, a voz feminina respondesse ou solicitasse a voz masculina como um contraponto (MILA, 1993), indicando uma constituição subjetiva do "eu" através desse "chamar o outro", o que pode nos fazer pensar no estatuto dessa mulher, no ponto específico de seu discurso que aponta a demência.

Lucia entra numa dinâmica de invocação que implicaria tanto num reconhecimento do outro como na sua falta, como o significante da ausência na presença dessa voz esvaziada de sentido, inaudível.

Lacan (1964) denominou o termo Invocante ou Vociferante para tratar de um circuito, uma pulsão adotada pelo sujeito do inconsciente que faz chamar. Mas há uma diferença entre a demanda e a invocação. Na demanda, o sujeito estaria numa posição de dependência absoluta em relação ao outro, porque ele the favorece o poder de ouvi-lo bem ou não. A demanda é 
compreendida como uma exigência absoluta feita ao outro para manifestar-se no aqui e agora.

Mas ao contrário, o sujeito invocante é retirado dessa dependência, pois não se trata mais de uma demanda endereçada a um outro, mas bem de uma invocação, supondo que uma alteridade possa advir de onde o sujeito, pura possibilidade, seria chamado a tornar-se.

Lucia invoca Edgardo, insere-o em seu discurso que não endereça a ninguém, mas que constitui a significação do ser. Dessa impossibilidade de poder ser do outro, dessa relação de potência, presumiria uma violência, pois se refere a algum tipo de apropriação de força. A possibilidade de perda é um poder-perder, e usar a voz para chamar Edgardo é uma espécie de poder obscuro que lhe foge às mãos, é violência sobre si mesma. A impossibilidade de compreensão do que ela mesma está dizendo torna o conhecido um desconhecido. É um movimento inverso das relações estabelecidas praticáveis. Há um circuito reverso nesse movimento de ouvir e falar, ouvir-se e fazer-se ouvir. Ao mesmo tempo, Lucia se distingue na ópera por sua voz fina e penetrante, que transpassa por tons que sobem e descem, afiados como lâmina, narrando a alucinação de que estaria na fonte com Edgardo. Ela está tão imersa num estado de delírio que poderíamos lembrar do mito das cigarras narrado por Adriana Cavarero (2011), em que elas teriam sido homens que, embevecidos pelo canto das musas, transformaram-se no inseto e passaram a apenas cantar, representando a figura ambígua e metamórfica do delírio que faz cantar até a morte. Ou cantar a própria morte.

No centro do mito, tal qual o delírio poético, repousaria um"atordoamento que domina e encanta, um prazer que apaga os instintos vitais, um canto que atrai e mata exatamente como aquele das sereias" (CAVARERO, 2011, p. 1).

A pretexto da loucura, podemos perceber o ornamento vocal e a intensidade dramática exigida à interprete deste papel. Testam, por sua vez, o virtuosismo de um canto soprano ligeiro, isto é, um agudo que vibra em mais alta frequência que um simples soprano. Esta técnica exige não só o alcance desse agudo e toda a densidade para proporcionar mais drama à heroína infeliz, mas também trinados, que poderiam ser descritos como a alteração rápida entre duas notas, geralmente distantes entre si, um semitom. A passagem Il dolce suono teria como acompanhamento original uma espécie de harmônica de vidro, instrumento que possui um timbre extremamente agudo, mas, por estar em desuso atualmente, foi substituído pela flauta.

Ouve-se a tessitura triste e sensual da soprano, que suspira, treme e delira em agudos que atravessam o corpo, a estrutura de borda da zona erógena, e ressoam no crânio. Em pleno desvario, Lucia crê que está na cerimônia de casamento com seu amado; dá gargalhadas e expressa todo um semblante de alegria. Esse semblante seria como uma máscara que usa sem 
consciência, como forma de suportar o real e não viver em carne viva. Neste apogeu, lança-se ao chão e acredita estar em núpcias, tira suas luvas enquanto fantasia sobre o prazer que dividiria com Edgardo. Mas apenas consigo mesma se relaciona, num fluxo corpóreo que vai do gozo à tristeza. Poderíamos repensar a invocação pulsante, dita aqui anteriormente e teorizada por Lacan, como uma "voz que procura outra voz". E é nessa medida que a música da orquestra comparece como que em uma resposta possível diante do impossível de se obter uma resposta do outro. Traz, cifradamente, algo sobre a posição singular de um sujeito para com esse objeto. Ou seja, quando Lucia chama, só a música lhe responde, pois ela não fala a ninguém.

Do ponto de vista da expressão, a voz musical, para Deleuze (1977), seria essencialmente uma voz desterritorializada, quer dizer, haveria cantos que não são necessariamente música, apesar de muito próximos. É o caso, ainda de acordo com Deleuze, do "tra la la".

Bem, a voz enquanto comunicação possui um território, mas no momento em que é correspondida a cada sílaba, uma notação musical - esse "tra la la" - ela perde seu território e se torna pronunciamento vocal, é mecanizada, é agenciamento vocal; não lida mais com uma operação de significados aos quais estamos acostumados. Aqui, ela aparece como a expressão de uma voz sonora pura, infantil, a voz da não consciência. Desterritorializada, ela implica no caráter único do ser, significa que o ser é Voz e que ele próprio se diz.

A mulher que a voz se torna ou que faz surgir é ela mesma uma mulher desterritorializada em seu conteúdo. O evento dessa voz aponta para uma pessoa sonora, mas em uma expressão de transe ou de delírio. Um fenômeno acústico no contexto da desrazão.

Seu canto insano estaria tão próximo do essencial quanto "o grito de mulher" que anuncia, ao longo dos corredores do castelo de Macbeth, que "a Rainha morreu" (FOUCAULT, 1961, p. 46). O grito teria se tornado "inacessível pelo filtro do saber institucional". Ele é, para Foucault, uma "rara e solitária expressão de uma experiência completamente e plenamenete trágica da loucura sem equivalente algum em uma cultura como a nossa. Pois nossa cultura sempre colocou a loucura à distância.” (1961, p.45).

Lucia foi levada, contra a vontade, a se casar pela ausência do objeto de sua paixão, e o retorno desse objeto a acusa de um ato contra seu coração desesperado, o que a faz matar. Nesse ponto, a verdade vem à tona, na e através da loucura que, provocada pela ilusão de um desfecho, acaba por desfazer por si só o mal entendido do qual ela é simultaneamente a causa e o efeito. Em outras palavras, ela faz surgir o verdadeiro problema que pode ser assim verdadeiramente levado a seu termo: a morte. A morte da potência, o aniquilamento de qualquer possibilidade de alcançar a pessoa amada, 
representada nessa cena justamente pelo doce som de uma voz sem destino, fadada à surdez.

Trata-se ainda do vazio da existência, não mais reconhecido como termo exterior e final, simultaneamente ameaça e conclusão; ele é sentido do interior como forma contínua e constante da existência. É a loucura como vida imperecível da morte, ou, segundo Foucault (Id.), a loucura agindo como o “jáestá-aí da morte”. Este vazio é o grito equivocado dos espíritos, a sobrevida na condição quase imortal que lhe permite uma completa desconexão dos pensamentos e assim lhe confere a capacidade de criar uma nova lógica que não reconhece limites.

Ao longo do século XIX, período em que a ópera foi composta, a configuração político-territorial da Itália passava pelo processo de unificação, o que fez aflorar um certo enaltecimento do indivíduo concernente à identidade cultural. O romantismo no campo das artes atuou como resposta a essas necessidades.

Mas pensemos na música que durante a tempestade revolucionária culminou numa dispensão da música tão somente instrumental e assume então uma outra função, menos aristocrática e mais social, com o melodrama modo de inserir um texto falado na forma de cantar. O descontentamento e a limitação do indivíduo se traduziam em uma insatisfação dos sentimentos, explicitamente da paixão ardente. Evidenciava aspectos psicológicos e afetivos em uma espécie de apologia ao amor como o único bem, a única verdade da vida. Nos teatros, de acordo com Mila (1993), a intensão passa a ser a de confrontar ideais e comportamentos com a própria experiência sentimental, exaltando o indivíduo e uma vida mais intensa. As óperas de Donizetti possuem, quase como um emblema, uma patologia do amor infeliz (Id., p.265); manifestada expressivamente nas mulheres e nas exaltações do coro, podemos citar além da personagem Lucia, Anna Bolena e Lucrezia Borgia. De fato, sua ópera é conhecida por tocar uma "verdade nua e nostálgica do canto popular" (Id.), sendo simples, mas expressiva. Entretanto, em oposição ao habitual no melodrama romântico italiano, Lucia di Lammermoor não encerra sua última cena com o brilho da protagonista nem com a exaltação do coro, mas com sua morte por um provável suicídio não mostrado no palco nem propriamente dito, mas é o desfecho que o espectador prontamente supõe.

Alguns anos após Donizetti ter escrito essa peça, ele próprio enlouqueceu pela sífilis. Isolado num espaço físico e moral de exclusão, pois, em se tratando de uma doença venérea, adquiri-la era considerado um feito da desordem e devassidão, teria escrito, já em delírio, sua última ópera, Dom Sebastião. Vem a falecer em 1848.

Por fim, retorno à Kristeva para inferir que a possibilidade do desatino é ameaçadora e abstrata, e, na ópera de Donizetti, ela se apresenta na harmonia vocal e na língua morta que anuncia o possível suicídio de Lucia. 
Esconde uma obsessão por algo enterrado vivo e que nunca será traduzido para não traí-lo. Refiro-me ao amor impossibilitado que continuará murado na cripta psíquica do luto e exasperando o corpo-túmulo.

\section{REFERÊNCIAS}

CAVARERO, Adriana. Vozes plurais: filosofia da expressão vocal. Belo Horizonte: Editora da UFMG, 2011.

DELEUZE, Gilles. Sur la musique. 1977. Disponível em: < http://www.leterrier.net/deleuze/anti-oedipe1000plateaux/1808-03-77.htm>. Acesso em: 11.ago.2012.

FOUCAULT, Michel. Folie et Déraison. Histoire de la folie à l'âge classique. Paris: Plon, 1961.

KRISTEVA, Julia. Sol negro: depressão e melancolia. Rio de janeiro: Rocco, 1989.

LACAN, Jacques (1964). O Seminário, Livro 11 - Os quatro conceitos fundamentais da psicanálise. 2. ed. Rio de Janeiro: Jorge Zahar, 1998. . Propos sur la causalité psychique. Ecrits. Paris: Seuil, 1966.

MILA, Massimo. Breve storia della musica. 3. ed. Torino: Einaudi, 1993. 